Original Research Paper

\title{
Evaluasi Ekologis Pohon Pelindung Kampus Universitas Mataram
}

\author{
Suripto $^{1 *}$, Siska Yunita Aksari² \\ 1, 2 Program Studi Biologi, FPMIPA, Universitas Mataram, Mataram, Indonesia
}

DOI: https://doi.org/10.29303/jpmpi.v3i2.565

Sitasi:. Suripto., \& Aksari, S. Y. (2020). Evaluasi Ekologis Pohon Pelindung Kampus Universitas Mataram. Jurnal Pengabdian Magister Pendidikan IPA, 3(2)

\section{Article history}

Received: 25 Oktober

Revised: 15 Nopember

Accepted: 29 Desember

*Corresponding Author:

Suripto, Program Studi Biologi, FPMIPA, Universitas Mataram, Mataram, Indonesia.

Email: suriptobio@unram.ac.id

\begin{abstract}
Abstrak: Kampus Universitas Mataram memiliki pohon-pohon peneduh kampus hampir di semua unit. Beberapa keberadaan pohon masih cukup ideal sehingga dapat memenuhi fungsi estetis maupun ekologis, namun juga terdapat pohon-pohon di dalam lingkungan kampus yang menunjukkan adanya permasalahan. Permasalahan yang terjadi pada pohon-pohon berupa penyimpangan-penyimpangan dendrogram pohon dari arsitektur idealnya berupa kemiringan tegakan pohon dan kecondongan tajuk. Permasalahan pohon tersebut bukan saja dapat menurunkan nilai estetik dan nilai ekologis dalam kampus, akan tetapi juga dapat meningkatkan resiko bahaya terhadap properti dalam kampus seperti gedung-gedung kuliah, laborataorium, kantor dan kendaraan serta masyarakat yang sedang beraktivitas di dalam kampus. Oleh karena itu kegiatan pengabdian ini sangat penting dilakukan dalam mengembangkan kajian tentang evaluasi ekologis pohon pelindung di Kampus Universitas Mataram, dimana nantinya kajian ini dapat dimanfaatkan sebagai ilmu dasar untuk melakukan evaluasi ekologis pohon pelindung dan menjadi agen sosialisasi sekaligus pelopor dalam menjaga dan merawat pohon peneduh kampus, sehingga secara berkesinambungan keberadaan pohon- pohon peneduh di kampus Universitas Mataram tetap memenuhi fungsi estetis dan ekologis.
\end{abstract}

Kata Kunci: Evaluasi Ekologis, Declivity, Inclination, Kampus, Pohon Pelindung

\section{Pendahuluan}

Kehadiran pohon-pohon di suatu tempat bukan saja dapat meningkatan nilai estetik dan nilai properti saja tetapi juga dapat meningkatkan nilai ekologis di lingkungan tersebut. Namun demikian dapat juga terjadi pengaruh sebaliknya, bila keberadaan pohon-pohon tersebut tidak ideal seperti susunan sebaran pohon yang tidak sesuai, adanya pohon-pohon yang tidak sehat, terjadinya kerusakan-kerusakan pada pohon dan adanya polapola arsitektur yang menyimpang karena tidak adanya perawatan yang memadai.

Kampus Universitas Mataram memiliki pohon-pohon peneduh kampus hampir di semua unit. Beberapa keberadaannya masih cukup ideal sehingga dapat memenuhi fungsi estetis maupun ekologis. Namun demikian sebagian besar dari pohon-pohon yang ada di dalam lingkungan kampus menunjukkan adanya permasalahan pohon berupa kerusakan batang utama ataupun cabang, juga pembusukan dan pelapukan batang (Suripto et al., 2019).

Permasalahan lain yang terjadi pada pohonpohon adalah terjadinya penyimpanganpenyimpangan dendrogram pohon dari arsitektur idealnya yang berupa kemiringan tegakan pohon dan kecondongan tajuk. Permasalahan pohon tersebut bukan saja dapat menurunkan nilai estetik dan nilai ekologis dalam kampus, akan tetapi juga dapat meningkatkan resiko bahaya terhadap properti dalam kampus seperti gedung-gedung kuliah, laborataorium, kantor dan kendaraan serta 
masyarakat yang sedang beraktivitas di dalam kampus tersebut. Pohon dengan kemiringan tegakan $30 \%$ atau lebih dan dengan kecondongan tajuk $30 \%$ atau lebih masing-masing atau bersamasama akan memiliki tingkat resiko bahaya sedang hingga sangat tinggi (Halle et al., 1978; Hasanuddin, 2013).

Oleh karena itu kegiatan ini sangat penting dilakukan dalam mengembangkan kajian tentang evaluasi ekologis pohon pelindung di Kampus Universitas Mataram, dimana nantinya dapat dimanfaatkan sebagai ilmu dasar untuk melakukan evaluasi ekologis pohon pelindung dan menjadi agen sosialisasi serta pelopor dalam menjaga dan merawat pohon peneduh kampus, sehingga secara berkesinambungan keberadaan pohon-pohon peneduh di kampus Universitas Mataram tetap memenuhi fungsi estetis dan ekologis.

\section{Metode}

Kegiatan ini dilaksanakan selama 25 hari terhitung mulai tanggal 6 Juli 2020 sampai dengan 30 Juli 2020 di kampus Universitas Mataram, Jalan Majapahit Nomor 62, Kecamatan Selaparang, Kota Mataram, Provinsi Nusa Tenggara Barat.

Alat dan bahan yang di gunakan dalam kegiatan ini adalah camera fujifilm S4500, senter/pointer, Busur derajat, Rollmeter, kompas, alat tulis berupa logbook, bolpoint dan pensil, pohon-pohon yang bermasalah, serta alat bahan lainnya yang berfungsi untuk menunjang proses praktik kerja lapangan mengenai evaluasi ekologis pohon pelindung di kampus Universitas Mataram.

Kegiatan ini dilaksanakan dengan metode jelajah dengan mengamati langsung dan mengambil data bukti-bukti (evidences) penyimpangan arsitektur pohon beradasarkan kecondongan tajuk (declivity) dan kemiringan tegakan (inclination) pohon. Pengambilan data dilakukan melalui pemotretan, pengukuran-pengukuran dan wawancara dengan para ekspert yang mengetahui riwayat perawatan yang telah dilakukan terhadap pohon sampel. Kemudian pengolahan data dilakukan untuk menentukan resiko bahaya dari pohon-pohon sampel yang diamati.

\section{a. Declivity}

Declivity merupakan parameter yang digunakan dalam menentukan kelas resiko tumbang suatu pohon yang merupakan suatu penyimpangan arsitektur pohon berdasarkan kecondongan tajuknya. Untuk menentukan kecondongan tajuk dibutuhkan alat untuk mengukur jari jari tajuk (kiri dan kanan) dari suatu pohon. Oleh karena itu alat yang diperlukan dalam mengukur jari-jari tajuk ini adalah roll meter dan pointer. Kemudian hasil pengukuran dicatat pada log book untuk selanjutnya dianalisis resiko tumbangnya berdasarkan parameter kecondongan tajuk.

b. Inclinasi

Inclinasi merupakan parameter yang digunakan untuk menentukan kelas resiko tumbang suatu pohon yang merupakan suatu penyimpangan arsitektur pohon berdasarkan kemiringan tegakannya. Untuk menentukan kemiringan tegakan dibutuhkan alat yaitu busur derajat dan alat yang membantu sebagai patokan tegakan sehingga dapat ditentukan berapa derajat kemiringan tegakan suatu pohon. Setelah melakukan pengukuran maka hasilnya dicatat pada log book untuk selanjutnya dianalisis resiko tumbangnya berdasarkan kemiringan tegakan pohon.

\section{ANALISIS DATA}

a. Declivity

Resiko tumbang suatu pohon berdasarkan declivity-nya dapat dibagi menjadi 5 kelas:

1. 1: $<1,2 \mathrm{~m}=$ Resiko Bahaya Sangat Rendah

2. 1: $(1,2-1,8) \mathrm{m}=$ Resiko Bahaya Rendah

3. 1: $(1,8-2,4) \mathrm{m}=$ Cukup Berbahaya

4. 1: $(2,4-3,0) \mathrm{m}=$ Berbahaya

5. $1:>3 \mathrm{~m}=$ Sangat Berbahaya

\section{b. Inclinasi}

Resiko tumbang suatu pohon berdasarkan inclinasi-nya dapat dibagi menjadi 5 kelas:

1. $<6,7 \%$ atau $<6^{\circ}=$ Resiko Bahaya Sangat Rendah

2. $6,7-13 \%$ atau $6-12^{\circ}=$ Resiko Bahaya Rendah

3. $13-26 \%$ atau $12-24^{\circ}=$ Cukup Berbahaya

4. $26-33 \%$ atay $24-30^{\circ}=$ Berbahaya

5. $>33 \%$ atau lebih dari $33^{\circ}=$ Sangat Berbahaya

\section{Hasil dan Pembahasan}

Universitas Mataram merupakan kampus yang memiliki banyak pohon pelindung di sepanjang jalannya. Jenis pohonnya pun bervariasi mulai dari pohon mahoni, pohon ketapang, pohon 
jambu, pohon jati dan banyak jenis pohon lainnya yang memiliki fungsi ekologis sebagai pohon pelindung kampus, juga memberikan nilai estetis/keindahan di lingkungan kampus Universitas Mataram. Oleh karena itu dipilihlah lokasi yaitu Kampus Universitas Mataram untuk melakukan kegiatan ini yang bertujuan untuk menganalisis resiko tumbang pohon pelindung kampus terutama untuk wilayah Fakultas Teknik yang memiliki area hutan dan menjadi fakultas yang memiliki jalan utama yang sering dilewati oleh pengendara atau pejalan kaki baik mahasiswa maupun dosen, juga wilayah lainnya di Kampus Universitas Mataram yang memiliki pohon-pohon yang beresiko tumbang.

Tabel 1. Hasil Pengukuran Resiko Tumbang

\begin{tabular}{|c|c|c|c|c|c|c|}
\hline \multirow[t]{2}{*}{ No } & \multirow{2}{*}{$\begin{array}{c}\text { Pohon } \\
\text { ke- }\end{array}$} & \multirow[t]{2}{*}{ Lokasi } & \multicolumn{2}{|c|}{ Jari Jari } & \multirow{2}{*}{$\begin{array}{l}\text { Kemiri- } \\
\text { ngan } \\
\left({ }^{\circ}\right)\end{array}$} & \multirow[t]{2}{*}{ Gambar } \\
\hline & & & $\begin{array}{l}\text { Kiri } \\
(\mathrm{m})\end{array}$ & $\begin{array}{c}\text { Kanan } \\
\text { (m) }\end{array}$ & & \\
\hline 1. & Pohon 1 & Fak. Teknik & 2 & 2,5 & 0 & \\
\hline 2. & Pohon 2 & Fak. Teknik & 10 & 0 & 15 & \\
\hline
\end{tabular}




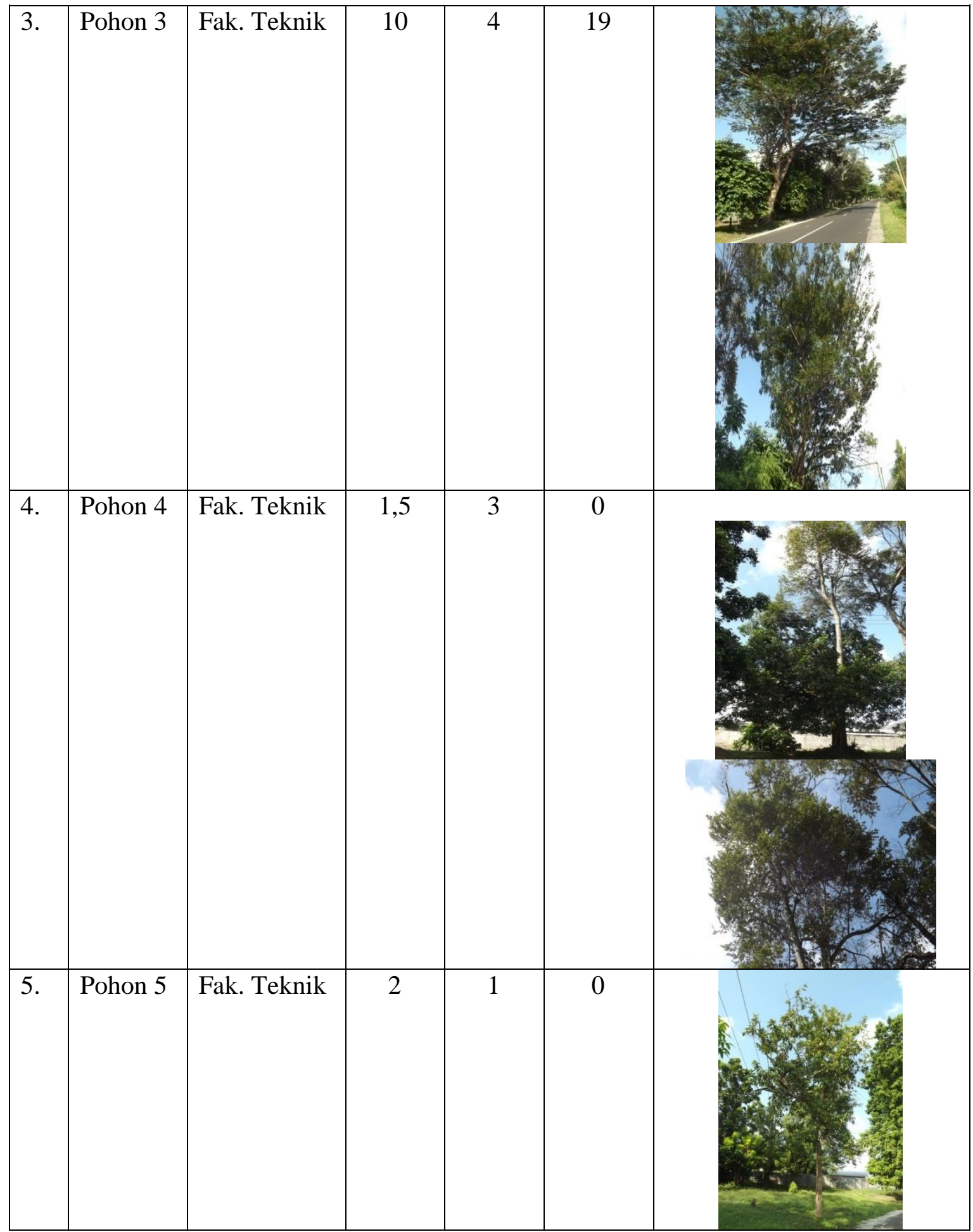




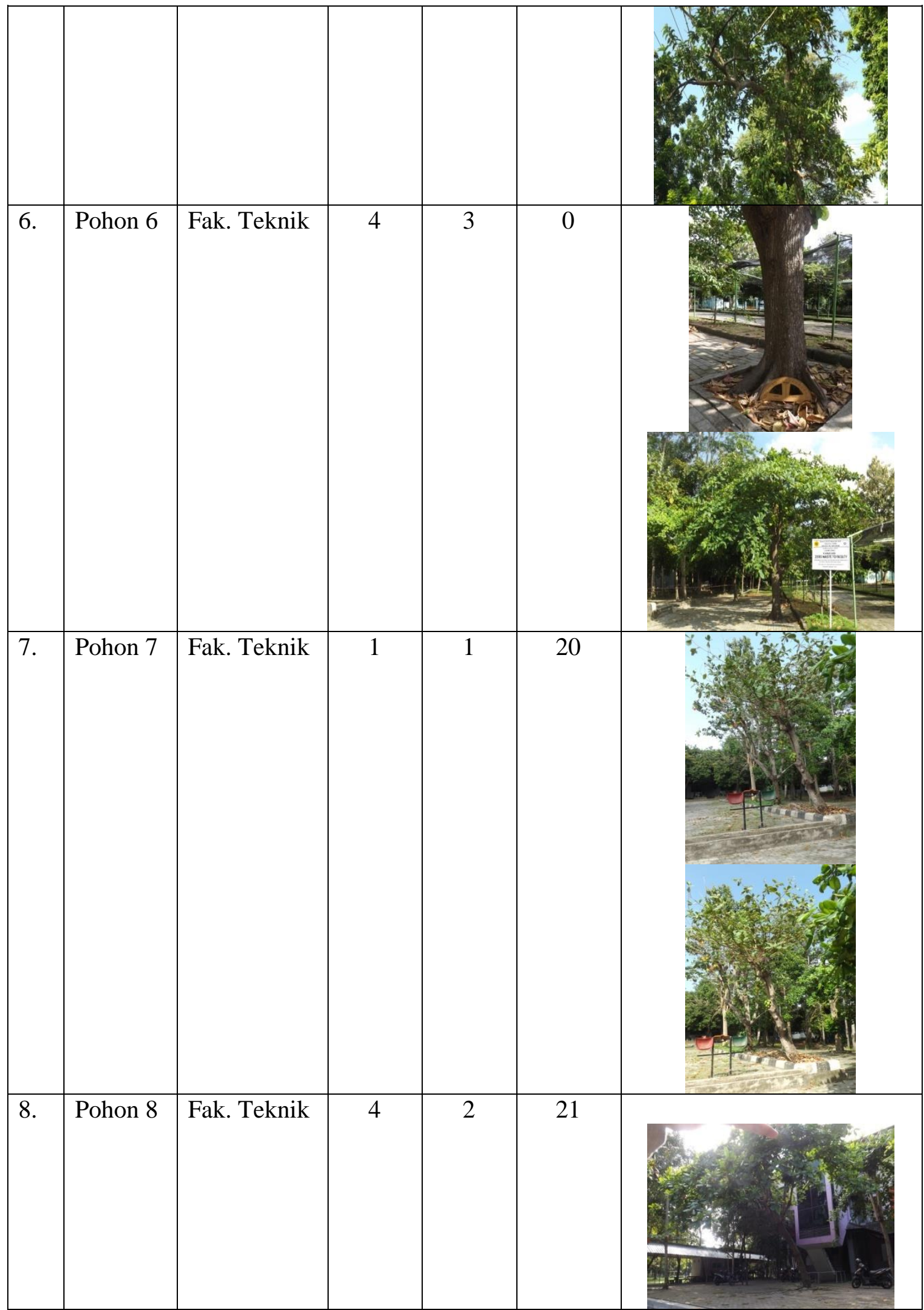




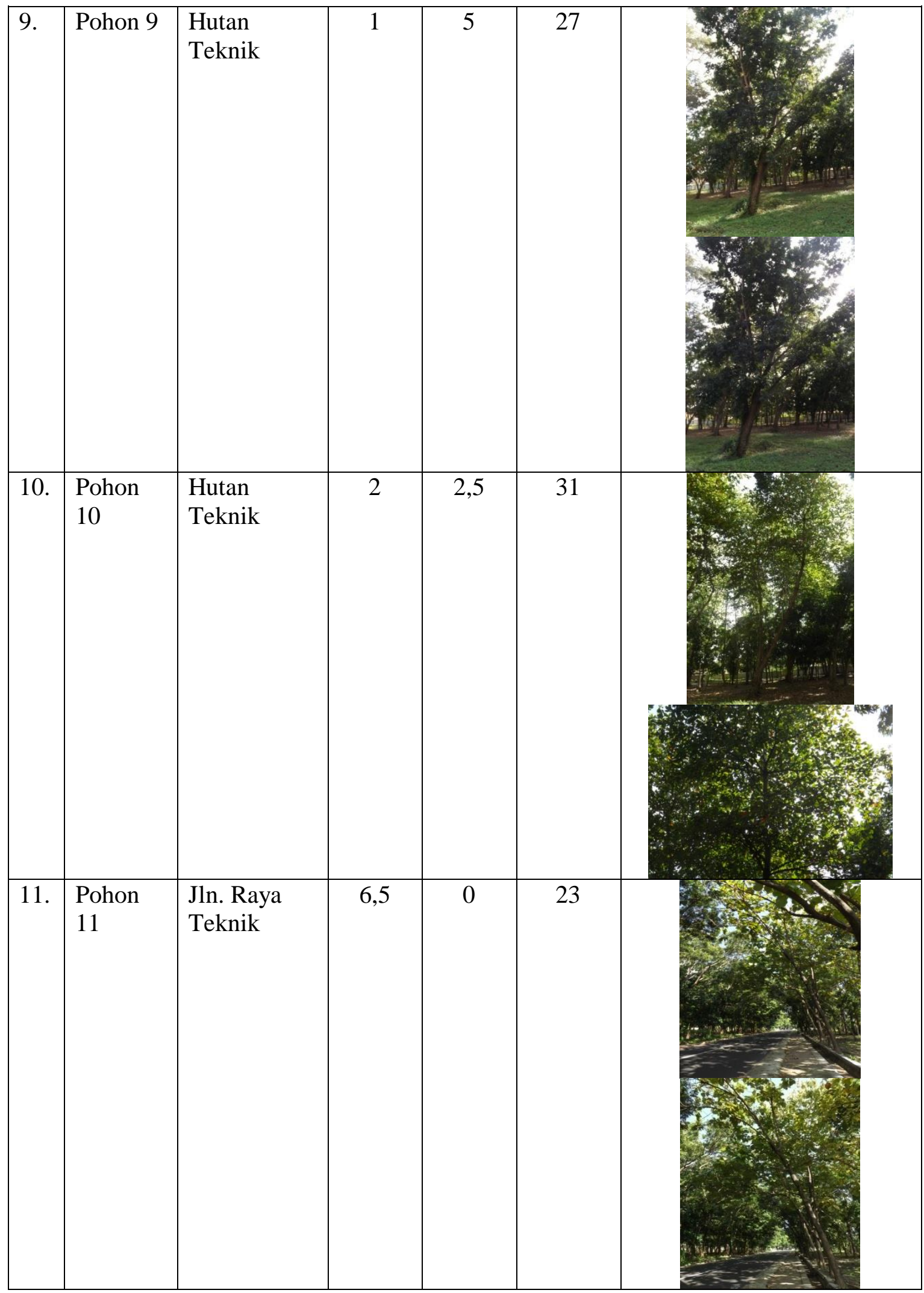




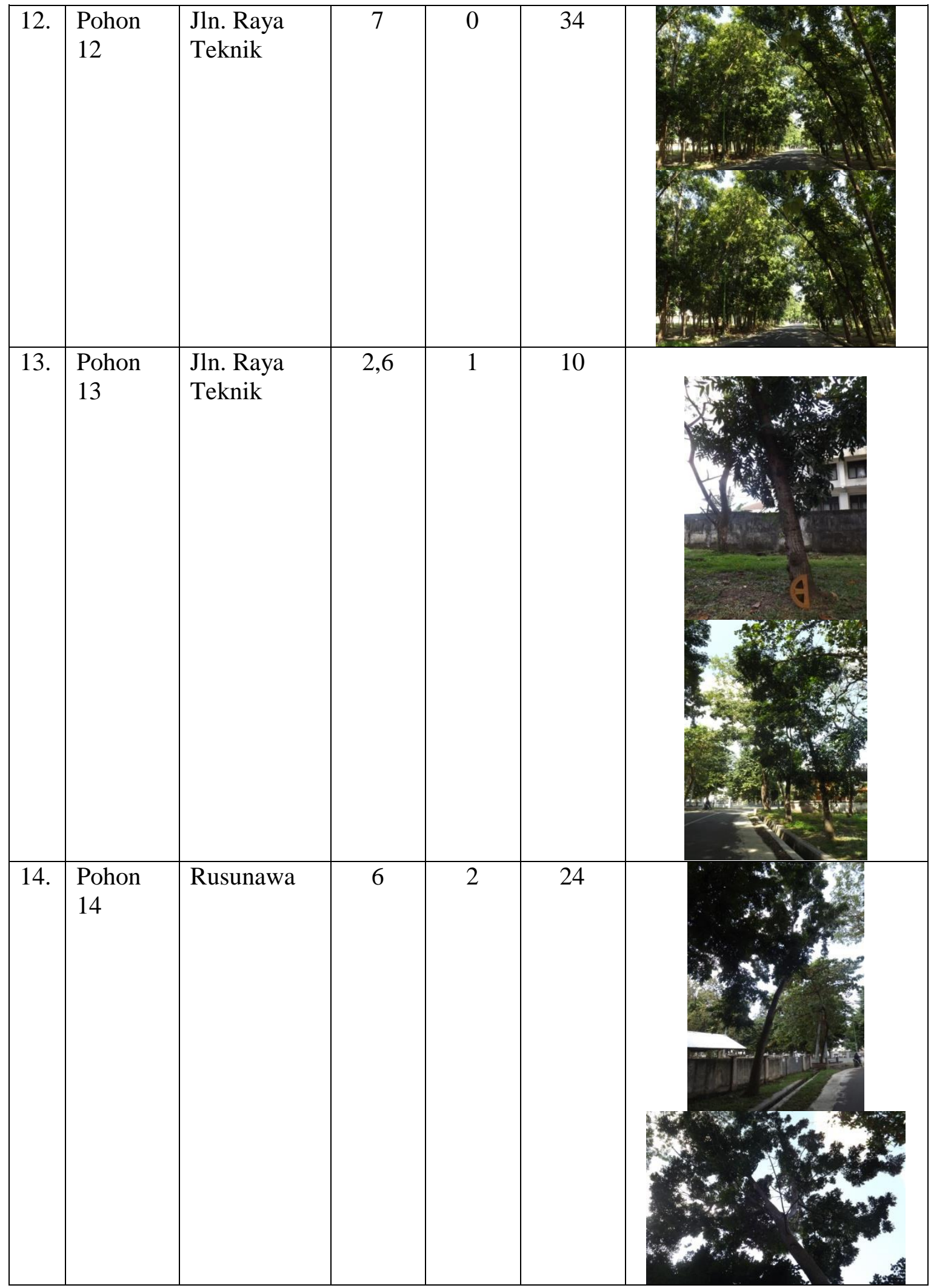




\begin{tabular}{|c|c|c|c|c|c|}
\hline 15. & $\begin{array}{l}\text { Pohon } \\
15\end{array}$ & $\begin{array}{l}\text { Jln. Raya } \\
\text { FKIP }\end{array}$ & 8 & 2 & 40 \\
\hline 16. & $\begin{array}{l}\text { Pohon } \\
16\end{array}$ & $\begin{array}{l}\text { Jln. Raya } \\
\text { FISIPOL }\end{array}$ & 5 & 5 & 0 \\
\hline 17. & $\begin{array}{l}\text { Pohon } \\
17\end{array}$ & $\begin{array}{l}\text { Jln. Raya } \\
\text { Teknik }\end{array}$ & 0 & 5 & 12 \\
\hline
\end{tabular}


Tabel 2. Hasil Kegiatan:

\begin{tabular}{|c|c|c|c|c|c|c|c|c|c|c|c|}
\hline \multirow[t]{2}{*}{ NO. } & \multirow[t]{2}{*}{ Pohon ke- } & \multicolumn{5}{|c|}{ Dec } & \multicolumn{5}{|c|}{ Inc } \\
\hline & & 1 & 2 & 3 & 4 & 5 & 1 & 2 & 3 & 4 & 5 \\
\hline 1. & Pohon ke-1 & & $\checkmark$ & & & & $\checkmark$ & & & & \\
\hline 2. & Pohon ke-2 & & & & & $\checkmark$ & & & $\checkmark$ & & \\
\hline 3. & Pohon ke-3 & & & & $\checkmark$ & & & & $\checkmark$ & & \\
\hline 4. & Pohon ke-4 & & & $\checkmark$ & & & $\checkmark$ & & & & \\
\hline 5. & Pohon ke-5 & & & $\checkmark$ & & & $\checkmark$ & & & & \\
\hline 6. & Pohon ke-6 & & $\checkmark$ & & & & $\checkmark$ & & & & \\
\hline 7. & Pohon ke-7 & $\checkmark$ & & & & & & & $\checkmark$ & & \\
\hline 8. & Pohon ke-8 & & & $\checkmark$ & & & & & $\checkmark$ & & \\
\hline 9. & Pohon ke-9 & & & & & $\checkmark$ & & & & $\checkmark$ & \\
\hline 10. & Pohon ke-10 & & $\checkmark$ & & & & & & & $\checkmark$ & \\
\hline 11. & Pohon ke-11 & & & & & $\checkmark$ & & & $\checkmark$ & & \\
\hline 12. & Pohon ke-12 & & & & & $\checkmark$ & & & & & $\checkmark$ \\
\hline 13. & Pohon ke-13 & & & $\checkmark$ & & & & $\checkmark$ & & & \\
\hline 14. & Pohon ke-14 & & & & $\checkmark$ & & & & & $\checkmark$ & \\
\hline 15. & Pohon ke-15 & & & & & $\checkmark$ & & & & & $\checkmark$ \\
\hline 16. & Pohon ke-16 & $\checkmark$ & & & & & $\checkmark$ & & & & \\
\hline 17. & Pohon ke-17 & & & & & $\checkmark$ & & $\checkmark$ & & & \\
\hline
\end{tabular}

Kegiatan ini berjudul Evaluasi Ekologis Pohon Pelindung Kampus Universitas Mataram. Kegiatan ini dilaksanakan selama 25 hari terhitung mulai tanggal 6 Juli 2020 sampai dengan 30 Juli 2020 di kampus Universitas Mataram, Jalan Majapahit Nomor 62, Kecamatan Selaparang, Kota Mataram, Provinsi Nusa Tenggara Barat. Kegiatan ini dilaksanakan dengan metode jelajah untuk mengamati langsung dan mengambil data bukti- 
bukti (evidences) penyimpangan arsitektur pohon beradasarkan kecondongan tajuk (declivity) dan kemiringan tegakan (inclination) pohon. Pengambilan data dilakukan melalui pemotretan, pengukuran-pengukuran dan wawancara dengan para ekspert yang mengetahui riwayat perawatan yang telah dilakukan terhadap pohon sampel. Kemudian pengolahan data dilakukan untuk menentukan resiko bahaya dari pohon-pohon sampel yang diamati.

Declivity merupakan salah satu parameter yang digunakan dalam menentukan kelas resiko tumbang suatu pohon yang merupakan suatu penyimpangan arsitektur pohon berdasarkan kecondongan tajuknya. Sedangkan inclinasi merupakan parameter yang digunakan untuk menentukan kelas resiko tumbang suatu pohon yang merupakan suatu penyimpangan arsitektur pohon berdasarkan kemiringan tegakannya.

Pohon mempunyai kenampakan seperti bentuk tajuk, percabangan, bentuk daun, bentuk dan ukuran buah, bentuk dan warna bunga dan lain-lain, dari berbagai unsur tersebut pohon dapat memberikan fungsi pada suatu ruang, oleh karenanya setiap pohon mempunyai fungsi yang berbeda-beda pada perancangan suatu lanskap. Beberapa fungsi pohon yang dapat diterapkan anatara lain sebagai pengarah atau penunjuk jalan, sebagai peneduh, sebagai pembatas antar kawasan, sebagai penunjang keindahan, termasuk juga taman bermain yang dilengkapi permainan. Adapun kriteria umum kesesuaian pohon penyusun ruang terbuka hijau menurut Kaharudin (2002) adalah sebagai:

1. Penyerap debu

Sebagian besar debu akan terserap pada permukaan daun khususnya pada daun yang berbulu dan permukaan daun yang kasar, dan sebagian lagi akan terserap masuk memalui stomata.

2. Peredam kebisingan

Tanaman dapat meredam kebisingan walaupun tidak menghilangkannya dengan kerapatan yang tinggi pada pola penanamannya sehingga menyerupai tembok. Hidayat (2010).

3. Penepis bau

Tanaman dapat menyerap dan bau tidak sedap, dimana tanaman yang ditanam dapat mengeluarkan bau harum yang dapat menetralisir bau busuk dan menggantikan dengan bau harum.

4. Penahan angin

Menurut Dahlan (1992) tanaman yang mampu menahan angina memiliki ciri-ciri daun yang tidak mudah gugur, dahan kuat, tajuk tebal, rindang, akar tumbuh kedalam tanah dengan ukuran tanaman sedang sampai tinggi

5. Peneduh atau pembentuk iklim mikro

Sebagai tanaman peneduh syarat-syarat yang harus dipenuhi antara lain buahnya tidak terlalu besar, tidak menggugurkan daun, pohon kuat, pertumbuhan perakaran tidak terlalu cepat sehingga terhindar dari hama dan penyakit (Suraida, 2012)

6. Estetika

Keindahan atau estetika suatu tumbuhan akan ditamoilkan dalam bentuk tajuk, warna dan tekstur untuk mendapatkan komposisi yang lembut, indah dan menarik (Dahlan, 2004).

7. Produksi

Pohon dapat menghasilkan produk berupa kayu, buah, bunga serta manfaat lain yang secara tidak langsung dihasilkan.

8. Budaya

Beberapa pohon mempunyai makna tersendiri dalam kebudayaan dimasing-masing daerah.

Hal penting lainnya yang harus diketahui adalah faktor-faktor penyebab besarnya resiko tumbang suatu pohon. Faktor-faktor tersebt antara lain yaitu angin, apabila arah hembusan angin searah dengan arah fektor kecondongan tajuk maka pohon tersebut memiliki resiko tumbang yang lebih besar. Faktor kedua yaitu bentuk arsitektur pohon, jika bentuk suatu pohon dapat menjadikan air mengaliri batang hingga ke akar pada musim penghujan maka pohon tersebut memiliki resiko tumbang yang lebih besar juga. Hal ini dikarenakan, jika air hujan menyapu batang dan turun hingga ke akar maka tanah di sekitar akar akan tergerus, makin lama maka tanah yang menjadi pegangan akar akan berkurang sehingga pohon akan mudah tumbang. Selain itu juga bentuk akar sangat berpengaruh terhadap resiko tumbang suatu pohon, pohon yang memiliki perakaran jenis akar tunggang akan memiliki resiko tumbang lebih kecil dibandingkan dengan pohon dengan system perakaran serabut. Oleh karena itu baiknya didalam lingkungan kampus, saat melakukan penanaman pohon, dipilihlah 
pohon yang memiliki system perakaran tunggang karena system perakaran seperti ini dapar memegang tanah lebih kuat, sehingga dapat mengurangi resiko tumbang suatu pohon di lingkungan kampus, khususnya untuk kampus Universitas Mataram.

Dari data hasil kegiatan ini, dapat dilihat bahwa resiko tumbang pohon berdasarkan declivity-nya tarbanyak pada kelas 5 yaitu sebanyak 6 sample pohon dengan presentase sebesar yaitu $35,3 \%$. Kemudian untuk resiko tumbang pohon berdasarkan inclinasi-nya tarbanyak pada kelas 1 dan 3 yaitu masing-masing sebanyak 5 sample pohon, sehingga presentase masing-masing sebesar $29,4 \%$. Oleh karena itu sangat diperlukan edukasi atau pelatihan kepada petugas sarana kampus tentang bagaimana merawat pohon agar sesuai dengan arsitektur pohon yang selain memberikan keindahan juga dapat memberikan kenyamanan dan keamanan terkait fungsinya sebagai pohon pelindung di Kampus Universitas Mataram.

\section{Kesimpulan}

Kesimpulan dari Kegiatan Kerja Pratek (KP) ini adalah, untuk declivity, modusnya berada pada kelas 5 (sangat berbahaya) yaitu berjumlah 6 pohon dengan presentase sebesar yaitu $35,3 \%$, dengan rincian untuk kelas berbahaya (kelas 4 \& 5) berjumlah 8 pohon dengan presentase sebesar $47,1 \%$, untuk kelas sedang ( kelas 3) berjumlah 4 pohon dengan presentase $23,5 \%$, dan untuk kelas rendah (1 dan 2 ) berjumlah 5 pohon dengan presentase 29,4\%. Sedangkan untuk inclinasi modusnya berada pada kelas 1 (Resiko bahaya sangat rendah) dan kelas 3 (Cukup Berbahaya) yaitu masing-masing sejumlah 5 pohon. Jumlah pohon yang tergolong resiko tumbang kelas rendah adalah 7 pohon sehingga presentase untuk resiko tumbang kelas rendah ( $1 \& 2$ ) yaitu $41,2 \%$, kemudian untuk kelas sedang (kelas 3) berjumlah 5 pohon dengan presentase $29,4 \%$, dan untuk kelas Berbahaya dan sangat berbahaya (kelas 4 \& 5) berjumlah 5 pohon dengan presentase $29,4 \%$. Sehingga dengan begitu perlu diadakannya pelatihan untuk pegawai atau pengelola masingmasing unit lembaga kampus dalam merawat pohon-pohon yang ada di lingkungan kampus agar resiko bahaya dari pohon-pohon tersebut dapat dikurangi demi kenyamanan dan keselamatan civitas akademika Universitas Mataram saat berada di lingkungan kampus.

\section{Daftar Pustaka}

Hasanuddin (2013).Model arsitektur pohon hutan Kota banda Aceh sebagai penunjang praktikum Morfologi Tumbuhan. Jurnal EduBio Tropia. 1(1):51-60.

Halle, F., Oldeman, R.A.A. \& P.B. Tomlinson (1978). Tropical Trees and Forests: An Architectural Analysis. Cambride University Press.

Suripto, Ahyadi, H. \& A. Jupri (2019).Identifikasi Kerusakan Pohon Peneduh Di kampus Universitas Mataram. Kumpulan Kertas Kerja Mata Kuliah Ilmu Lingkungan. Laporan tidak dipublikasikan. Fakultas Matematika dan Ilmu Pengetahuan Alam Universitas Mataram.

Dahlan, E.N. 2004. Membangun Hutan Kebun (Garden City) Bernuansa Hutan Kota. Institut Pertanian Bogor. Bogor.

Kaharudin. 2002. Laporan Penelitian: Studi Kesesuaian Jenis Vegetasi di Yogyakarta. Fakultas Kehutanan UGM. Yogyakarta.

Hidayat, I.W. 2010. Kajian Fungsi Ekologi Jalur Hijau Jalan Sebagai Penyangga Lingkungan Pada Tol Jagorawi (Study Of The Ecological Function Of Roadside Greenery Os Environmental Bulfer On Jagorawi Highway). J. Manusia Dan Lingkungan. 17(2): $124-13$.

Suraida. 2012. Identifikasi Tumbuhan Penghijauan Sebagai Media Belajar Biologi. Jurnal Edu-Bio. Vol 3: 55-64. 